\title{
Muscle relaxation and increasing doses of propofol improve intubating conditions
}

\section{[Les myorelaxants et des doses élevées de propofol améliorent les conditions d'intubation]}

Thomas Lieutaud MD, ${ }^{*}$ Valérie Billard MD, ${ }^{*}$ Huguette Khalaf MD, ${ }^{*}$ Bertrand Debaene MD†

Purpose: Muscle relaxants and anesthetics are usually associated during intubation. However, their relative role to facilitate the process is not clearly defined. This study was designed to determine, during intubation: i) the relative role of anesthetics and atracurium-induced neuromuscular block and; ii) the effect of different doses of propofol in the presence of complete muscle block.

Methods: Patients were randomized to four groups and received fentanyl and a standardized anesthetic procedure. Patients from groups high $(\mathrm{H} ; n=45)$, medium $(M ; n=48)$ and low $(L ; n=47)$ received $2.5 \mathrm{mg} \cdot \mathrm{kg}^{-1}, 2.0 \mathrm{mg} \cdot \mathrm{kg}^{-1}$, and $1.5 \mathrm{mg} \cdot \mathrm{kg}^{-1}$ of propofol respectively. Atracurium $\left(0.5 \mathrm{mg} \cdot \mathrm{kg}^{-1}\right)$ was then injected and tracheal intubation performed once complete block was achieved at the orbicularis oculi. Patients from group without atracurium (WA; $n=20$ ) received propofol as in group $H$. Intubation was performed at the expected onset time of action of atracurium.

Results: Using the same dose of propofol, the incidence of good or excellent intubating conditions was 35\% without atracurium and 95\% with atracurium $(P<0.000$ I). In patients receiving atracurium, clinically acceptable intubating conditions were more frequently achieved in groups receiving the highest propofol doses (group $\mathrm{H}$ or $M$ vs group L; $P<0.03$ ).

Conclusion: Our study confirms the interaction between anesthesia and muscle relaxation to produce adequate intubating conditions. In the conditions described, intubating conditions were more dependent on atracurium-induced neuromuscular blockade than on anesthetics, but both atracurium and propofol improved intubating conditions.

Objectif : Agents d'anesthésie et curares sont souvent associés pour l'intubation. Cependant, leurs rôles respectifs pendant l'intubation ne sont pas clairement définis. Cette étude a pour objectif de différencier pour l'intubation i) l'effet des agents d'anesthésie de ceux du bloc moteur induit par l'atracurium et ii) le rôle de différentes doses de propofol couplées à un bloc moteur complet induit par l'atracurium.
Méthode : Les patients étaient randomisés en quatre groupes. Tous recevaient du fentanyl et une procédure d'anesthésie standardisée. Les patients des groupes high ( $\mathrm{H} ; n=45)$, medium ( $\mathrm{M} ; n=48)$, et low $(\mathrm{L} ; n=47)$ recevaient respectivement $2,5 \mathrm{mg} \cdot \mathrm{kg}^{-1}, 2,0 \mathrm{mg} \cdot \mathrm{kg}^{-1}$ et $1,5 \mathrm{mg} \cdot \mathrm{kg}^{-1}$ de propofol puis atracurium $0,5 \mathrm{mg} \cdot \mathrm{kg}^{-1}$. L'intubation était réalisée et cotée après qu'un bloc complet avait été obtenu à l'orbiculaire de l'œil. Les patients du groupe n'ayant pas reçu l'atracurium (WA) recevaient le propofol comme dans le groupe $H$, et étaient intubés après un intervalle de temps correspondant à celui du délai d'action supposé de l'atracurium.

Résultats : Chez les patients recevant des doses d'anesthésie équivalentes, les conditions d'intubation étaient significativement meilleures chez ceux recevant l'atracurium (groupe H) par rapport aux patients $W A(P<0,000 I)$. Pour les patients recevant de l'atracurium, les conditions d'intubation étaient significativement meilleures chez les patients du groupe $H$ ou M par rapport aux patients du groupe $L(P<0,03)$.

Conclusion : Les conditions d'intubation dépendent plus du bloc neuromusculaire que des agents d'anesthésie lorsque l'on attend l'installation complète du bloc. Cependant, les conditions d'intubation dépendent aussi du rôle des agents d'anesthésie lors de l'intubation avec une curarisation complète.

$\mathrm{I}$ NTUBATION of the trachea using direct laryngoscopy can be performed without any neuromuscular blocking drug. ${ }^{1}$ Intubating conditions then depend on the depth of anesthesia (i.e., the type, the dose or the combination of anesthetics) and are related to the time interval between the injection of anesthetics and laryngoscopy. ${ }^{2-4}$

Muscle relaxants are widely used to facilitate tracheal intubation but are never used without anesthetics. In this case, the quality of tracheal intubation

From the Départements d'anesthésie, Institut Gustave Roussy, ${ }^{*}$ Villejuif; CHU de Poitiers, $\dagger$ Poitiers, France.

Present correspondence address: Dr Thomas Lieutaud, Département d'anesthésie-réanimation; Hôpital Neurologique Pierre Wertheimer,

B.P. Lyon Montchat, 69394 Lyon, Cedex 03, France. Phone: 33- 4723575 76; Fax: 334723575 30;

E-mail: thomas.lieutaud@chu-lyon.fr

Presented in part at the 5th congress of the European Society of Anesthesiology, London, June 1996.

Accepted for publication February 26, 2002.

Revision accepted September 6, 2002. 
depends on the relaxation induced by the abolition of upper airway reflexes related to central nervous system depression induced by $i v$ or inhaled anesthetics, and by paralysis of the laryngeal muscles induced by muscle relaxants. The onset time of paralysis is different from a muscle relaxant to another and from one muscle group to another (adductor pollicis vs laryngeal adductor muscles). This onset time is directly related to the dose and inversely related to potency for nondepolarizing relaxants. It is $\leq 60 \mathrm{sec}$ for succinylcholine $^{5}$ rapacuronium ${ }^{6}$ and rocuronium with a dose superior to $1.0 \mathrm{mg} \cdot \mathrm{kg}^{-1}, 7$ and it is superior to two minutes for vecuronium, atracurium and rocuronium with a dose of twice the $\mathrm{ED}_{95}$.

The longer the onset time of the muscle relaxant, the longer the time interval between the administration of anesthetics and tracheal intubation if intubation is performed with respect to muscle paralysis. The clinical consequence of this delay is a decrease in the depth of anesthesia at the time of laryngoscopy.

To date, the literature can be summarized as follows: 1) following the administration of short-onset neuromuscular relaxants such as succinylcholine, intubating conditions are similar to those obtained with anesthetic combinations such as propofol (2-2.5 $\left.\mathrm{mg} \cdot \mathrm{kg}^{-1}\right)$ and alfentanyl $\left(30 \mu \mathrm{g} \cdot \mathrm{kg}^{-1}\right) \cdot{ }^{8-12}$ These results confirm that anesthetics have a major impact on intubating conditions when intubation is performed rapidly after induction of anesthesia; 2) following the administration of non-depolarizing muscle relaxants, intubating conditions are always better than those obtained in the absence of relaxants. ${ }^{13-18}$

As a result, the longer the time interval between the induction of anesthesia and intubation, the more important is muscle paralysis to obtain clinically acceptable intubating conditions. However, the interaction between various doses of an induction drug and a muscle relaxant of intermediate-onset time of action on intubating conditions in the clinical setting remains unclear. To test this interaction, we performed a twostep controlled randomized study to compare: i) the effect of atracurium in patients receiving the same doses of anesthetics, and ii) the effect of three different doses of anesthetic in patients receiving the same dose of atracurium, on intubating conditions.

\section{Materials and methods}

Selection of patients

After obtaining approval from our local Ethics Committee, a written informed consent was obtained from 170 ASA physical status I or II patients (18-65 yr), scheduled for abdominal or breast surgery. Exclusion criteria included the presence of an abnormal airway, ${ }^{19}$ sig-

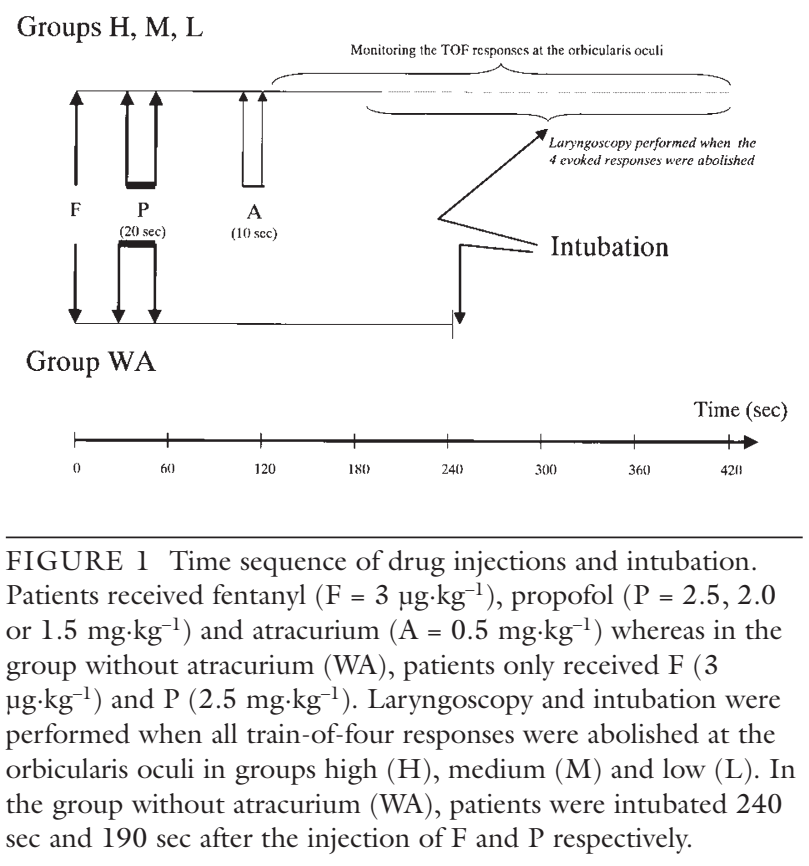

nificant cardiovascular, respiratory, hepatic, neuromuscular or renal disease, or the administration of any drug known or suspected to interact with neuromuscular transmission. On arrival in the operating room, standard monitors were applied and patients were randomly assigned to one of four groups high $(\mathrm{H})$, medium $(\mathrm{M})$, low (L) or without atracurium (WA).

\section{Anesthesia procedure}

The protocol is summarized in Figure 1. All patients received fentanyl $3 \mu \mathrm{g} \cdot \mathrm{kg}^{-1}$ over ten seconds. Time T0 corresponded to the end of fentanyl injection. Thirty seconds later, propofol was injected over $20 \mathrm{sec}: 2.5$ $\mathrm{mg} \cdot \mathrm{kg}^{-1}$ in groups $\mathrm{H}(n=50)$ and WA $(n=20), 2.0$ $\mathrm{mg} \cdot \mathrm{kg}^{-1}$ in group $\mathrm{M}(n=50)$ and $1.5 \mathrm{mg} \cdot \mathrm{kg}^{-1}$ in group $\mathrm{L}(n=50)$. Sixty seconds later, atracurium $0.5 \mathrm{mg} \cdot \mathrm{kg}^{-1}$ was injected in groups $\mathrm{H}, \mathrm{M}$ and $\mathrm{L}$ over ten seconds. Atracurium was not used in group WA. After loss of consciousness, supramaximal train-of-four (TOF) stimulations $(30 \mathrm{~mA})$ were applied on the temporal branch of the facial nerve every ten seconds, as described previously, ${ }^{20}$ atracurium was injected thereafter. In all patients, the same observer visually assessed the evoked responses at the orbicularis oculi. Bag-mask ventilation was used until tracheal intubation was performed. Onset of action of atracurium was defined as the interval between the end of atracurium injection and disap- 


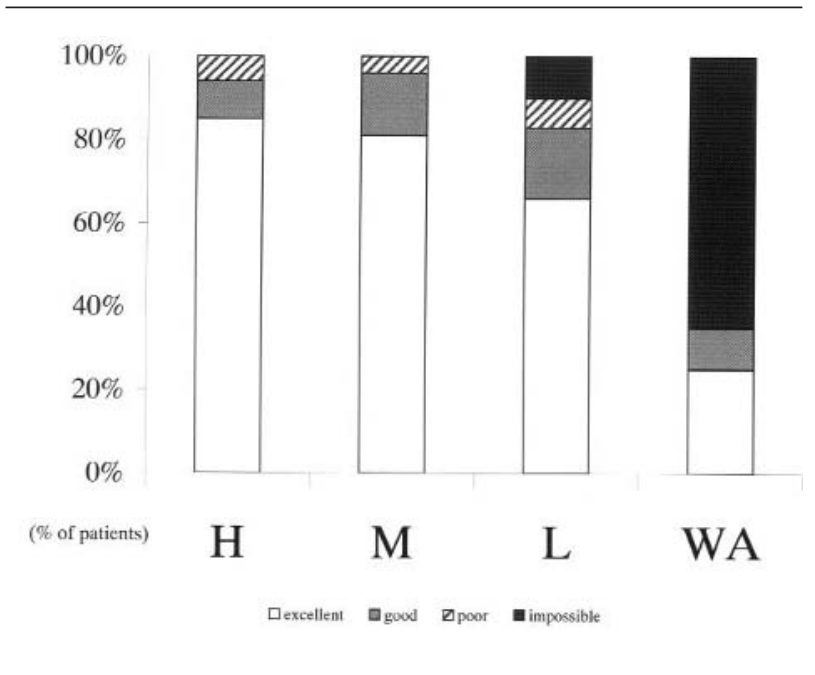

$\overline{\text { FIGURE } 2 \text { Intubating condition scores in each group (expressed }}$ in percentage, \%). Intubating conditions were scored as excellent, good, poor or impossible in patients receiving high $(\mathrm{H})$, medium (M) or low (L) doses of propofol. ${ }^{*} \mathrm{P}<0.03$ between groups $\mathrm{H}$ and $\mathrm{M}$ vs group $\mathrm{L} ;{ }^{*} \mathrm{P}<0.0001$ between group $\mathrm{H}$ vs group without atracurium (WA).

pearance of the four muscular responses at the orbicularis oculi. In groups $\mathrm{H}, \mathrm{M}$ and $\mathrm{L}$ trachea was intubated at that time. In group WA, trachea was intubated $240 \mathrm{sec}$ after the end of fentanyl injection i.e., $190 \mathrm{sec}$ after propofol injection, a delay corresponding to the expected onset time of atracurium.

The same physician, blinded to the anesthetic procedure, performed all intubations. Intubating conditions were graded using the scoring scale initially described by Krieg et al. ${ }^{21}$ (Table I). This scale distributes intubating conditions into four classes (excellent, good, poor, impossible). In groups $\mathrm{H}, \mathrm{M}$ and $\mathrm{L}$, intubating conditions were then pooled as "clinically acceptable" (excellent or good) or "not clinically acceptable" (poor or impossible). ${ }^{22}$

When laryngoscopy was scored as "impossible", patients were not evaluated for vocal cords position or severity of cough, and intubating conditions were classified as "impossible". When vocal cords were "closed", intubating conditions were also scored as "impossible". In these patients, intubation was performed after an injection of additional propofol $(20-50 \mathrm{mg}$ ) and atracurium $\left(0.5 \mathrm{mg} \cdot \mathrm{kg}^{-1}\right.$; only in group WA $)$.

When complete blockade at the orbicularis oculi was not achieved $300 \mathrm{sec}$ after atracurium injection, direct laryngoscopy was not attempted and the patient was excluded from the study. In these patients, intubation was performed once complete neuromuscular blockade was obtained with an incremental dose of atracurium $\left(0.2 \mathrm{mg} \cdot \mathrm{kg}^{-1}\right)$ in combination with propofol $(50-100 \mathrm{mg})$ to avoid awareness.

All patients were interviewed the day after surgery and questioned about awareness. None reported recall of awareness during anesthesia and surgery.

\section{Statistical analysis}

The table of randomization (four groups) was designed to assign two patients in each group every eight inclusions. The allocation of the patient was sealed in an opaque envelope, which was opened at the arrival in the operating room. Intermediate analysis was planned after every 80 patients. Statistical analyses were performed using ANOVA, a Chi-square or an exact Chi-square test as appropriate. Results are expressed as mean $\pm \mathrm{SD}$. A $P$ value of 0.05 or less was considered to indicate a statistically significant difference. We expected that intubating conditions would be optimal in $40 \%$ of patients in groups WA, and in $80 \%$ of patients in group $\mathrm{H}$. Thus, 40 patients in each group would be sufficient to detect a difference of $40 \%$ between group WA and $\mathrm{H}$ with a power of $80-90 \%$ at $P<0.05$. As we planned to perform an intermediate analysis, 50 patients in each group were studied.

\section{Results}

Groups were similar with respect to age, sex and body mass index (Table II). Ten patients were excluded from the study because the onset time of atracurium-induced neuromuscular block was over $300 \mathrm{sec}$ at the orbicularis oculi (group H: five patients; group M: two patients; group L: three patients; no statistical difference). Complete block at the orbicularis oculi was achieved subsequently in all cases after the administration of an extra bolus of atracurium $\left(0.2 \mathrm{mg} \cdot \mathrm{kg}^{-1}\right)$. All these patients had intubation classified as clinically acceptable.

We scored 160 intubations (group $\mathrm{H}: n=45$; group M: $n=48$; group L: $n=47$; group WA: $n=20$ ). The study was discontinued in group WA after the first intermediate analysis because the incidence of "clinically not acceptable" (poor and impossible) intubating conditions was unacceptable (13 of 20 patients, 65\%). Intubating conditions are summarized in Figure 2. Intubating conditions did not differ in groups $\mathrm{H}, \mathrm{M}$ and $\mathrm{L}$, and were significantly better than in group WA $(P<0.0001)$ when they were scored on a four-class scale. Intubating conditions scored as "not clinically acceptable" were significantly more frequent in group L $(14.9 \%)$ than in groups $\mathrm{H}(4.4 \%)$ or $\mathrm{M}(2.1 \% ; P<0.03)$. Laryngoscopy was scored as impossible on the first attempt in 19 patients (14 in group WA, five in group $\mathrm{L}$, none in groups $\mathrm{M}$ and $\mathrm{H} ; \mathrm{P}<0.001$ group WA $v$ s 
TABLE I Intubating condition scores adapted from references 21 and 22

\begin{tabular}{|c|c|c|c|c|}
\hline \multicolumn{5}{|l|}{ Assessment } \\
\hline Laryngoscopy & Easy & Fair & Difficult & Impossible \\
\hline Vocal cords & Open & Moving & Closing & Closed \\
\hline Coughing & None & Slight & Clear & Severe \\
\hline Points & 1 & 2 & 3 & 4 \\
\hline \multirow{2}{*}{$\begin{array}{l}\text { Classes } \\
\text { Points }\end{array}$} & Excellent & Good & Poor & Impossible \\
\hline & $3-4$ & $5-7$ & $8-10$ & $11-12$ \\
\hline \multirow{2}{*}{$\begin{array}{l}\text { Intubating } \\
\text { conditions }\end{array}$} & - & - & - & - \\
\hline & \multicolumn{2}{|c|}{ Clinically acceptable } & \multicolumn{2}{|c|}{ Clinically not acceptable } \\
\hline
\end{tabular}

TABLE II Demographic characteristics of the study population

\begin{tabular}{lllll}
\hline Groups & $H$ & $M$ & $L$ & $W A$ \\
$n$ & 45 & 48 & 47 & 20 \\
\hline BMI & $23.3(3.9)$ & $23.7(3.2)$ & $23.1(3.2)$ & $23.6(3.4)$ \\
Age & $50.4(10.7)$ & $52.9(11.8)$ & $51.3(12.6)$ & $56.3(11.9)$ \\
Sex-ratio (F/M) & $42 / 3$ & $41 / 7$ & $39 / 8$ & $18 / 2$ \\
\hline
\end{tabular}

Data are expressed as mean $( \pm \mathrm{SD}) . \mathrm{H}=$ high; $\mathrm{M}=$ medium; $\mathrm{L}=$ low; $\mathrm{WA}=$ without atracurium; $\mathrm{BMI}=$ body mass index; $\mathrm{F}=$ female; $M=$ male

TABLE III Laryngoscopy scores

\begin{tabular}{lllll}
\hline $\begin{array}{l}\text { Groups } \\
n(\%)\end{array}$ & $H$ & $M$ & $L$ & $W A^{*}$ \\
& 45 & 48 & 47 & 20 \\
\hline Easy & $39(87)$ & $42(88)$ & $35(73)$ & $13(65)$ \\
Fair & $4(9)$ & $5(10)$ & $8(17)$ & $1(5)$ \\
Difficult & $2(4)$ & $1(2)$ & 0 & $2(10)$ \\
Impossible & 0 & 0 & $4(8)$ & $4(20)$ \\
\hline
\end{tabular}

${ }^{*} P<0.001$ vs other three groups. $\mathrm{H}=$ high; $\mathrm{M}=$ medium; $\mathrm{L}=$ low; $\mathrm{WA}=$ without atracurium.

other groups). All these patients were intubated successfully after receiving additional propofol/atracurium. Results concerning vocal cord position, ease of laryngoscopy, or reaction to insertion of the tracheal tube and/or cuff inflation are summarized in Tables III, IV and $\mathrm{V}$. The mean onset time of atracurium-induced neuromuscular block at the orbicularis oculi was $166 \pm$ $62 \mathrm{sec}$. Mean onset time of action among patients in groups $\mathrm{H}, \mathrm{M}$ and $\mathrm{L}$ was not different $(167 \pm 66,151 \pm$ 54 and $177 \pm 65 \mathrm{sec}$ respectively). Onset time was longer than the theoretical onset time $(120 \mathrm{sec})$ used for the group not receiving atracurium $(P<0.05)$.

\section{Discussion}

In the conditions of our study, we confirmed the interaction of anesthetics and muscle relaxants on
TABLE IV Position of vocal cords

\begin{tabular}{lllll}
\hline $\begin{array}{l}\text { Groups } \\
n(\%)\end{array}$ & $H$ & $M$ & $L$ & $W A^{*}$ \\
\hline Open & 45 & 48 & 43 & 16 \\
Moving & $38(84)$ & $39(81)$ & $29(68)$ & $5(30)$ \\
Closing & $5(11)$ & $4(8)$ & $11(26)$ & $1(5)$ \\
Closed & $2(4)$ & $5(11)$ & $2(4)$ & 0 \\
\hline
\end{tabular}

${ }^{*} P<0.001$ vs other three groups. $\mathrm{H}=$ high; $\mathrm{M}=$ medium; $\mathrm{L}=$ low; $\mathrm{WA}=$ without atracurium.

TABLE V Cough scores

\begin{tabular}{lllll}
\hline $\begin{array}{l}\text { Groups } \\
n(\%)\end{array}$ & $H$ & $M$ & $L$ & $W A^{*}$ \\
& 45 & 48 & 42 & 6 \\
\hline None & $21(47)$ & $24(50)$ & $15(36)$ & $2(33)$ \\
Slight & $16(35)$ & $17(35)$ & $16(39)$ & 0 \\
Clear & $8(18)$ & $7(15)$ & $8(18)$ & $1(17)$ \\
Severe & 0 & 0 & $3(7)$ & $3(50)$ \\
\hline
\end{tabular}

${ }^{*} P<0.001$ ps other three groups. $\mathrm{H}=$ high; $\mathrm{M}=$ medium; $\mathrm{L}=$ low; WA $=$ without atracurium.

intubating conditions and differentiated their relative effects. This study first showed that, in patients receiving the same dose of anesthetics, with or without atracurium, intubating conditions depend much more on neuromuscular blockade than on depression of the central nervous system induced by anesthetics $(95 \%$ vs $35 \%$ of good or excellent intubating conditions in group $\mathrm{H}$ vs group WA; $P<0.0001)$. Second, this study showed that intubating conditions were significantly influenced by the dose of anesthetic administered in combination with atracurium when intubation is performed once complete muscle blockade is achieved at the orbicularis oculi (group $\mathrm{H}$ or $\mathrm{M}$ vs group $\mathrm{L} ; P<0.03$ ).

In the first part of this study, we evaluated the relative role of muscle relaxants and anesthetics on intubating conditions. The high incidence of poor intubating conditions (65\%) obtained in the group not receiving atracurium was far different from the results reported in the literature on intubation without muscle relaxants. We suspect this is mainly due to the longer time interval used in our study between anesthetic injection and intubation (190 and $240 \mathrm{sec}$ for propofol and fentanyl respectively in comparison with the interval of 45-90 sec time usually reported in the literature). This long time interval was introduced in group WA to parallel the expected onset time of action of atracurium in group $\mathrm{H}$. This long time interval explains also why fentanyl was chosen instead of alfentanil. ${ }^{23}$ The delayed peak effect of fentanyl, as 
compared to that of alfentanil, was expected to correspond to the interval between fentanyl administration and laryngoscopy $(240 \mathrm{sec})$.

Atracurium was chosen because its onset of action at the laryngeal and orbicularis oculi muscles had already been documented. ${ }^{24}$ This value was considered to be similar between both muscle groups when it was reviewed recently. ${ }^{25}$ Mean onset time after atracurium $0.5 \mathrm{mg} \cdot \mathrm{kg}^{-1}$ observed in our study $(166 \pm 62 \mathrm{sec})$ was similar to that obtained in previous studies: $146 \pm 55$ $\sec ^{24} 141 \pm 7 \sec ^{26}$ and $129 \pm 33 \sec ^{27}$ after the same dose of atracurium. A similar value $(120 \mathrm{sec})$ was used to determine the moment of laryngoscopy in group WA.

Ten patients were excluded because the evoked muscular responses of the orbicularis oculi were still present five minutes after atracurium injection. Direct stimulation of the orbicularis oculi can be excluded since complete blockade was obtained after the injection of an extra dose of atracurium in all these patients and the airway secured under excellent conditions in all patients. Moreover, whatever the relaxant of intermediate onset of action used, orbicularis oculi monitoring is considered very acceptable. ${ }^{27}$

The second part of our study was designed to compare different levels of anesthesia during intubation with atracurium. Pharmacologically, the depth of anesthesia induced by propofol decreases from the time of bolus administration until laryngoscopy. Currently, the models used to induce different depths of anesthesia involve either a variation of the time interval from drug injection to intubation ${ }^{4}$ or a variation of the dose of anesthetics (opioids and/or narcotics) with a fixed time interval between drug injection and intubation. . $^{3,8,10,28}$ We used this second model in which the predetermined time interval governing intubation was dependent of the inter-individual variability of onset of action of atracurium at the orbicularis oculi.

Nevertheless, mean onset time of atracuriuminduced neuromuscular block was not different in groups $\mathrm{H}, \mathrm{M}$ and $\mathrm{L}$. The difference in intubating conditions was, thus, postulated to be due to the difference of the anesthesia depth obtained with the three propofol doses.

In our study, the decrease in the dose of propofol (to $1.5 \mathrm{mg} \cdot \mathrm{kg}^{-1}$ ) resulted in a significant decrease in the incidence of clinically acceptable intubating conditions while the patient's orbicularis oculi was completely paralyzed. From a clinical point of view, we advise to maintain a sufficient depth of anesthesia to avoid clinically unacceptable intubating conditions when intubation is delayed until complete muscle blockade is obtained.
In conclusion, this study confirmed the interaction between anesthetics and muscle relaxants to produce adequate intubating conditions. Propofol (1.5-2.5 $\left.\mathrm{mg} \cdot \mathrm{kg}^{-1}\right)$ and fentanyl $\left(3 \mu \mathrm{g} \cdot \mathrm{kg}^{-1}\right)$ have a limited influence on the quality of intubating conditions in comparison with non-depolarizing muscle relaxants of intermediate-onset of action when intubation is performed once complete block, as monitored at the orbicularis oculi, is achieved. Both atracurium and increasing doses of propofol improve intubating conditions.

\section{Acknowledgement}

The authors thank Claude Meistelman MD, for carefully reviewing the manuscript.

\section{References}

1 Lewis CB. Endotracheal intubation under thiopentone. An analysis of 200 cases. Anaesthesia 1948; 3: 113.

2 Barker P, Langton JA, Wilson IG, Smith G. Movements of the vocal cords on induction of anaesthesia with thiopentone or propofol. Br J Anaesth 1992; 69: 23-5.

3 Davidson JAH, Gillespie JA. Tracheal intubation after induction of anaesthesia with propofol, alfentanil and IV lignocaine. Br J Anaesth 1993; 70: 163-6.

4 McKeating K, Bali IM, Dundee JW. The effects of thiopentone and propofol on upper airway integrity. Anaesthesia 1988; 43: 638-40.

5 Meistelman C, Plaud B, Donati F. Neuromuscular effects of succinylcholine on the vocal cords and adductor pollicis muscles. Anesth Analg 1991; 73: $278-82$.

6 Debaene B, Lieutand T, Billard V, Meistelman C. ORG 9487 neuromuscular block at the adductor pollicis and the laryngeal adductor muscles in humans. Anesthesiology 1997; 86: 1300-5.

7 Magorian T, Flannery KB, Miller RD. Comparison of rocuronium, succinylcholine, and vecuronium for rapid-sequence induction of anesthesia in adult patients. Anesthesiology 1993; 79: 913-8.

8 Stevens JB, Vescovo MV, Harris KC, Walker SC, Hickey $R H$. Tracheal intubation using alfentanil and no muscle relaxant: is the choice of hypnotic important? Anesth Analg 1997; 84: 1222-6.

9 Beck GN, Masterson GR, Richards J, Bunting P. Comparison of intubation following propofol and alfentanil with intubation following thiopentone and suxamethonium. Anaesthesia 1993; 48: 876-80.

10 Scheller MS, Zornow MH, Saidman LJ. Tracheal intubation without the use of muscle relaxants: a technique using propofol and varying doses of alfentanil. Anesth Analg 1992; 75: 788-93.

11 Alcock R, Peachey T, Lynch M, McEwan T. Comparison of alfentanil with suxamethonium in facilitating naso- 
tracheal intubation in day-case anaesthesia. $\mathrm{Br} \mathrm{J}$ Anaesth 1993; 70: 34-7.

12 Harsten A, Gillberg L. Intubating conditions provided by propofol and alfentanil-acceptable, but not ideal. Acta Anaesthesiol Scand 1997; 41: 985-7.

13 Ueda N, Muteki T, Tsuda H, Masuda Y, Ohishi K, Tobata $H$. Determining the optimal time for endotracheal intubation during onset of neuromuscular blockade. Eur J Anaesthesiol 1993; 10: 3-8.

14 Barclay K, Eggers K, Asai T. Low-dose rocuronium improves conditions for tracheal intubation after induction of anaesthesia with propofol and alfentanil. Br J Anaesth 1997; 78: 92-4.

15 Lowry DW, Carroll MT, Mirakhur RK, Hayes A, Hughes $D$, O'Hare R. Comparison of sevoflurane and propofol with rocuronium for modified rapid-sequence induction of anaesthesia. Anaesthesia 1999; 54: 247-52.

16 Kahwaji R, Bevan DR, Bikhazi G, et al. Dose-ranging study in younger adult and elderly patients of ORG 9487, a new, rapid-onset, short-duration muscle relaxant. Anesth Analg 1997; 84: 1011-8.

17 Huizinga AC, Vandenbrom RH, Wierda JM, Hommes FD, Hennis PJ. Intubating conditions and onset of neuromuscular block of rocuronium (Org 9426); a comparison with suxamethonium. Acta Anaesthesiol Scand 1992; 36: 463-8.

18 Pino RM, Ali HH, Denman WT, Barrett PS, Schwartz $A$. A comparison of the intubation conditions between mivacurium and rocuronium during balanced anesthesia. Anesthesiology 1998; 88: 673-8.

19 Mallampati SR, Gatt SP, Gugino LD, et al. A clinical sign to predict difficult tracheal intubation: a prospective study. Can Anaesth Soc J 1985; 32: 429-34.

20 Donati F, Meistelman C, Plaud B. Vecuronium neuromuscular blockade at the diaphragm, the orbicularis oculi, and adductor pollicis muscles. Anesthesiology 1990; 73: 870-5.

21 Krieg N, Mazur L, Booij LH, Crul JF. Intubating conditions and reversibility of a new non-depolarizing neuromuscular blocking agent, Org NC45. Acta Anaesthesiol Scand 1980; 24: 423-5.

22 Viby-Mogensen J, Engbaek J, Eriksson LI, et al. Good clinical research practice (GCRP) in pharmacodynamic studies of neuromuscular blocking agents. Acta Anaesthesiol Scand 1996; 40: 59-74.

23 Scott JC, Ponganis KV, Stanski DR. EEG quantitation of narcotic effect: the comparative pharmacodynamics of fentanyl and alfentanil. Anesthesiology 1985; 62: 234-41.

24 Ungureanu D, Meistelman C, Frossard J, Donati F. The orbicularis oculi and the adductor pollicis muscles as monitors of atracurium block of laryngeal muscles. Anesth Analg 1993; 77: 775-9.
25 Plaud B, Debaene B, Donati F. The corrugator supercilii, not the orbicularis oculi, reflects rocuronium neuromuscular blockade at the laryngeal adductor muscles. Anesthesiology 2001; 95: 96-101.

26 Le Corre F, Pland B, Benhamon E, Debaene B. Visual estimation of onset time at the orbicularis oculi after five muscle relaxants: application to clinical monitoring of tracheal intubation. Anesth Analg 1999; 89: 1305-10.

27 Debaene B, Beaussier M, Meistelman C, Donati F, Lienhart $A$. Monitoring the onset of neuromuscular block at the orbicularis oculi can predict good intubating conditions during atracurium-induced neuromuscular block. Anesth Analg 1995; 80: 360-3.

28 Saarnivaara L, Klemola UM. Injection pain, intubating conditions and cardiovascular changes following induction of anaesthesia with propofol alone or in combination with alfentanil. Acta Anaesthesiol Scand 1991; 35: 19-23. 